\title{
North-Coast of Texel: \\ A Comparison between Reality and Prediction
}

\author{
Rob Steijn ${ }^{1}$ \\ Dano Roelvink ${ }^{2}$ \\ Dick Rakhorst ${ }^{3}$ \\ Jan Ribberink ${ }^{4}$ \\ Jan van Overeem ${ }^{1}$
}

\begin{abstract}
$\underline{\text { Abstract }}$
For an efficient protection of the north coast of the Dutch Waddensea island Texel, a long dam was constructed in 1995. The position of this dam is on the southern swash platform of the ebb tidal delta of the Eijerlandse Gat: the tidal inlet between the two Waddensea islands Texel and Vlieland. The long dam changed the hydro-morphological conditions in this tidal inlet. The changes in the inlet's morphology have been monitored through regular bathymetry surveys. This paper describes some of the most remarkable changes that occurred in the inlet after the construction of the long dam.

The impact of the long dam on the inlet's morphology and the adjacent shoreline stability has been examined with the use of a medium-term morphodynamic model. From a comparison between the observed and predicted morphological changes it followed that the model was able to simulate the large scale morphological response of the inlet system. However, on a smaller scale there were still important discrepancies between the observations and the predictions.
\end{abstract}

\section{Introduction}

The Dutch Government decided in 1990 to maintain the coastline at its 1990-position by means of artificial sand nourishments. However, at certain coastal sections, where nourishments appear to be less effective, alternative coastal protection methods could be considered. The north-coast of Texel (Figure 1) appeared to be such a coastal section.

Over a distance of some $6 \mathrm{~km}$, the north-coast of Texel has lost in the last decades on average about 0.5 million $\mathrm{m}^{3}$ sand per year. Before 1995 the maximum coastline retreat was $5-10 \mathrm{~m} /$ year at the most severely eroded northern sections. According to the formalised Dutch Coastal Defence Policy (Rijkswaterstaat, 1990), this erosion was combatted through regular sand nourishments. However, these nourishments became less and less effective. Alternative coastal protection measures were considered for this coast, like groynes, offshore breakwaters, long dam(s), revetments; most of them in combination with initial beach nourishment. Detailed numerical model studies were

\footnotetext{
1 Alkyon Hydraulic Consultancy \& Research, P.O. Box 248, 8300 AE Emmeloord, The Netherlands; fax: +31527610020

2 WLIDelft Hydraulics, P.O Box 177, $2600 \mathrm{MH}$ Delft, The Netherlands; fax: +31 152858582

3 Ministry of Public Works, Riłkswaterstaat, regional Directorate North Holland, P.O. Box 3119, 2001 DC Haarlem, The Netherlands; fax: +31235301752

4 University of Twente, P.O.Box 217,7500 AE Enschede, The Netherlands; fax: +31 534894040
} 


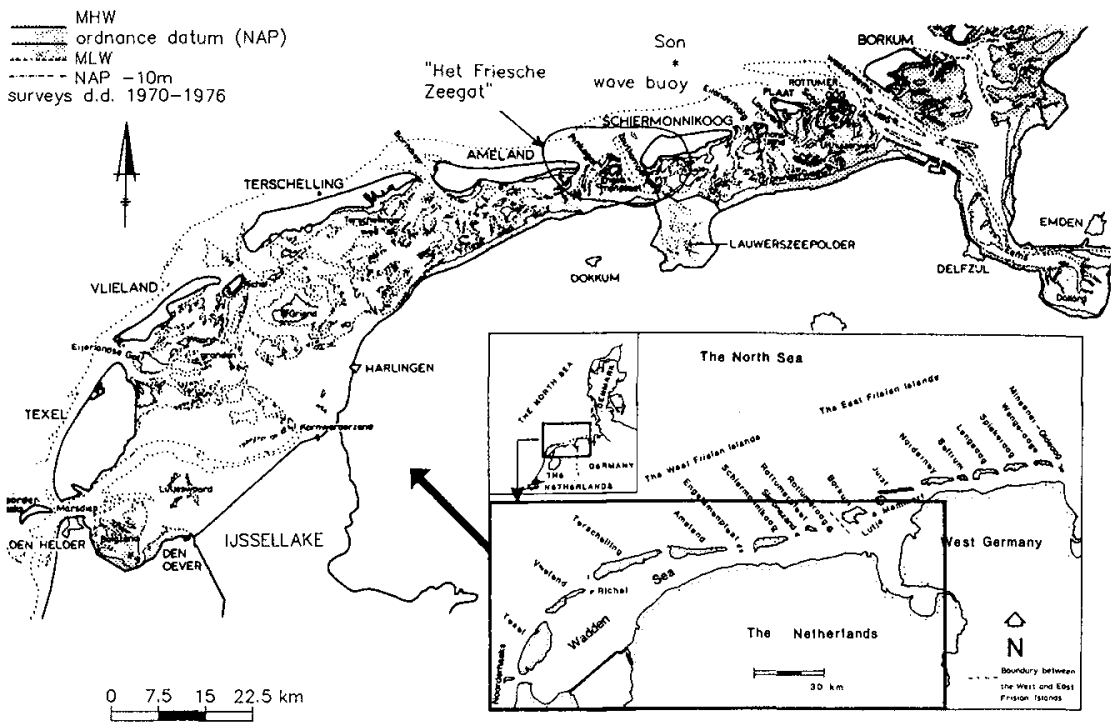

Figure 1 Geographical setting

carried out to investigate the effect of the alternative measures and their costefficiency to combat the erosion. A long dam (700 m from the MLW-line) was finally chosen (Rakhorst, De Wilde and Schot, 1997).

The long dam was constructed in 1995 at the northern end of the north coast of Texel (at RSP $30.5 \mathrm{~km}$ ), in combination with nourishment and dredging works. The morphological changes that took place afterwards were monitored, which gave valuable data for a comparison between predicted and actually observed morphological tidal inlet responses.

In recent years, process-based morpho-dynamical modelling has developed rapidly. In the present study the available dataset for the long dam case has been used to check and validate the model. The model parameters were set as much as possible identical as the ones in the "old model" from 1993, however this time with the latest versions of the applied software DELFT3D (Roelvink, Boutmy and Stam, 1998). A comparison between the renewed predictions (improved hindcast) and the field observations was made and valuable information was obtained on how to set up and operate similar models and to know their weak and strong points.

\section{The tidal inlet "Eijerlandse Gat"}

The ebb tidal delta, the inlet throat and the flood tidal basin are shown in Figure 2 (situation as in 1993; before the dam construction). On the ebb tidal delta, the pattern of tidal channels can clearly be recognised, as well as the presence of shallow areas and delta bars. The ebb-dominant inlet throat channel "Robbengat" will be of special 
importance for the present study. The flood tidal basin is, in contrast to the other Waddensea flood tidal basins, a closed basin: only during storms, exchange of water takes place across the watersheds.

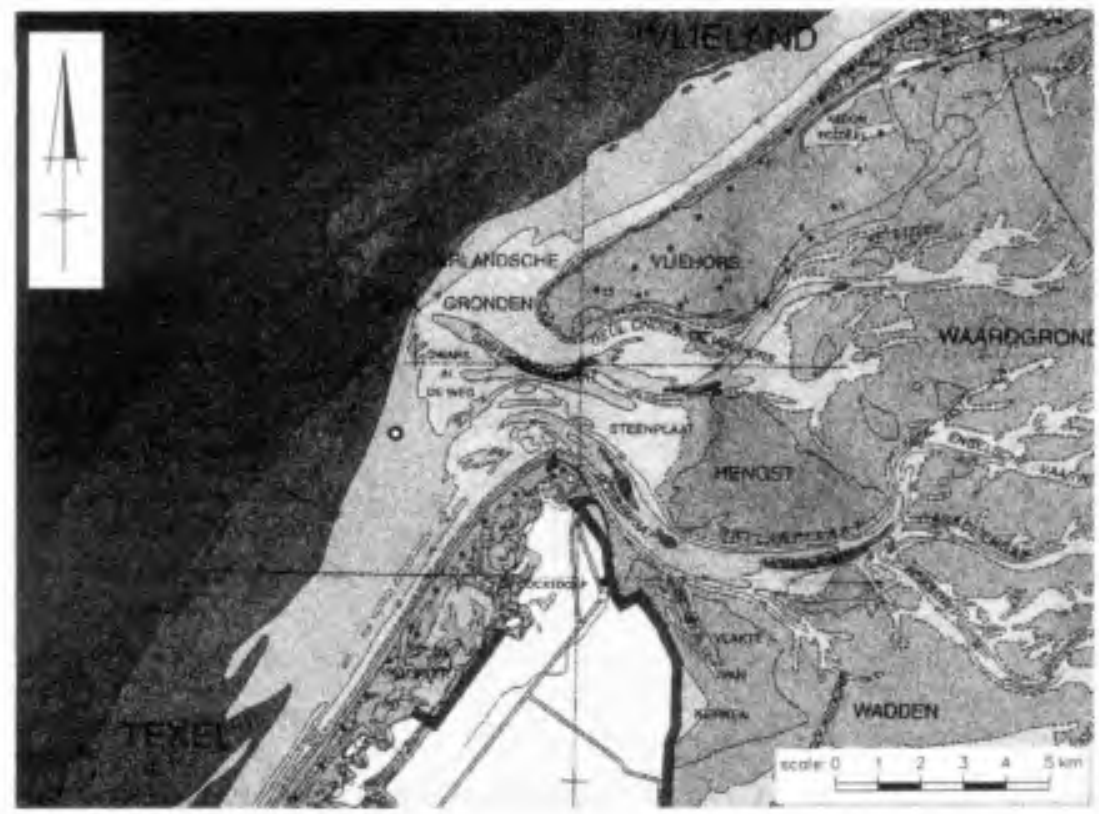

Figure 2 The tidal inlet "Eijerlandse Gat"

The particles size of the seabed and the beach sediments ranges between 150 and 350 $\mu \mathrm{m}$ : coarser in the tidal channels than on top of the shallow areas or on the beaches.

The tide is semi-diurnal with neap, mean and spring tidal ranges of, respectively, $1.35 \mathrm{~m}, 1.70 \mathrm{~m}$ and $1.90 \mathrm{~m}$. Tidal wave propagation is from south to north. Waves are moderate, with a mean annual wave height (at deep water) of $\mathrm{H}_{\mathrm{s}}=1.2 \mathrm{~m}$. The yearly average wind speed is $7 \mathrm{~m} / \mathrm{s}$ from south-southwesterly directions. Storms (larger than 7 Beaufort) mainly come from northwesterly directions.

\section{What has been done in the last decades?}

The southward migration of the Robbengat was stopped succesfully in 1948 and 1956 with the construction of two slope-protection schemes on the north-side of Texel (inside the inlet throat). Ongoing erosion of the north coast of Texel (south of the above-mentioned slope-protection works) was combatted in 1979, 1985 and 1990 by artificial sand nourishments of 2.5 to 3 million $\mathrm{m}^{3}$, each time. The actual lifetime of the last nourishment was shorter than what was expected beforehand. 
In the period 1990 - 1993 different studies were carried out to find more efficient methods to protect the north-coast of Texel (e.g. Negen, 1993, Ribberink and de Vroeg, 1991, 1992, Hartsuiker, 1991, Ribberink, de Vroeg and van Overeem, 1993, Rakhorst and Pwa, 1993 - all of them in Dutch and Ribberink, Negen and Hartsuiker, 1995). A first attempt for a full morpho-dynamic simulation of the tidal inlet, including a long dam alternative, was made by Negen (1993). Based on these effectstudies, which also included ecological and cost-benefits studies, it was concluded that a long dam at the northern end of Texel would be the most cost-effective for maintaining the north-coast of Texel.

In 1994 a 1.3 million $\mathrm{m}^{3}$ sand nourishment was carried out on the north coast of Texel. This was necessary as the 1994-position of the coastline had already receded behind the reference 1990 position. The sand for this nourishment was reclaimed from a borrow area below the MSL $-20 \mathrm{~m}$ depth contour (i.e. below the closure depth, so from outside the active coastal system).

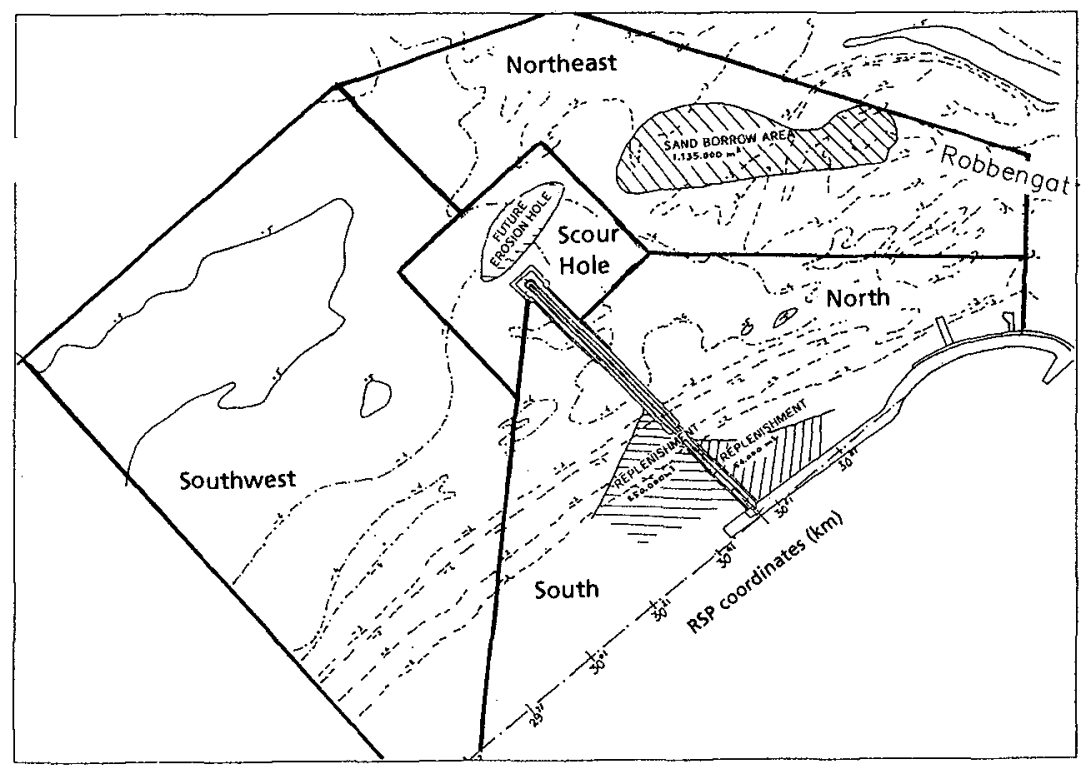

Figure 3 Drawing of the long dam and dredging works

Construction of the long dam at position RSP $30.5 \mathrm{~km}$ (Figure 2) commenced in April 1995. By July 1995, the dam had reached its most seaward tip at $700 \mathrm{~m}$ from the most seaward MLW-line; or $800 \mathrm{~m}$ from the dunefoot. Also in early 1995, an additional 0.7 million $\mathrm{m}^{3}$ sand was replenished along the north coast of Texel. Another 0.4 million $\mathrm{m}^{3}$ sand was placed in the neck of the dam (Figure 3), also to make the construction site better accessible for construction equipment. This 1.1 million $\mathrm{m}^{3}$ sand was borrowed by a cutter suction dredger from an area between the expected scour hole and the inlet channel Robbengat (Figure 3). The idea behind this was to initiate the 
development of a new ebb tidal channel in southward direction, and consequently to let the ebb tidal delta develop more in front of the north coast of Texel, which on the longer term could also benefit the sand balance of the north-coast of Texel.

\section{Observations}

The long dam and dredging works changed the tidal flow regime and wave conditions around and in the immediate vicinity of the dam. It also affected the tidal flow to and from the flood basin. Figure 4 shows for the area around the dam, the observed pattern of erosion and sedimentation between 1995 and 1997 (two-years period).
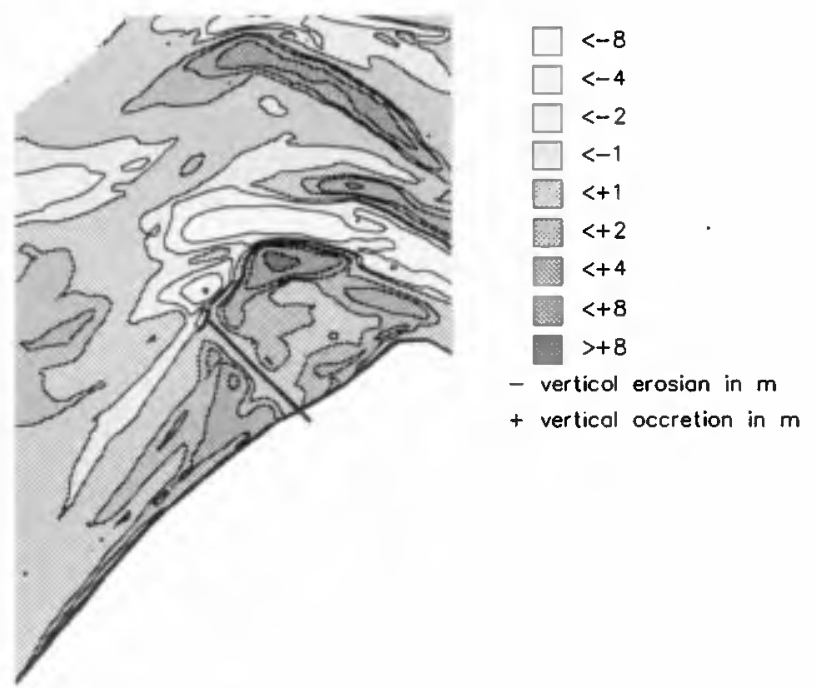

Figure 4 Observed sedimentation and erosion 1995 - 1997

The figure shows areas with significant erosion (such as in front of the tip of the dam, and to the north of the dredged borrow area), as well as areas with significant accretion (such as in the dredged borrow area and to the southwest of the ebb tidal delta). The figure also clearly shows the accretion along the coastlines on both sides of the dam. Below, some details of the observations are given:

\section{Scour hole}

The scour hole in front of the tip of the dam developed more rapidly than expected. The maximum depth reached MSL - $18 \mathrm{~m}$ already in september 1995, that is only two months after the dam was finished (note that the local depths at this point were only MSL $-5 \mathrm{~m}$ ). The slopes on the dam-side of the scour hole are very steep, namely 1:2 to 1:3 (vert:hor), which led to the placement of an extra rubble layer after completion of the dam and later again in December 1996 (Rakhorst, De Wilde and Schot, 1997). The wet volume of the scour hole in $\mathrm{m}^{3}$ below MSL $-5 \mathrm{~m}$ is given in Table 1 . 


\begin{tabular}{|c|c|c|}
\hline $\begin{array}{c}\text { Wet volume below } \\
\text { MSL }-5 \mathrm{~m}\left(\mathrm{~m}^{3}\right)\end{array}$ & $\begin{array}{c}\text { Time after dam } \\
\text { construction (months) }\end{array}$ & $\begin{array}{c}\text { Max. depth } \\
\text { (MSL - m) }\end{array}$ \\
\hline 0 & 0 & -5 \\
250,000 & 2.5 & -18 \\
350,000 & 8 & -16 \\
300,000 & 14 & -15 \\
300,000 & 20 & -13 \\
\hline
\end{tabular}

Table 1 Development of the scour hole.

The maximum depth reduced considerably in the winter of $1996 / 1997$, where it is noted that the winter of $1995 / 1996$ hardly had any westerly storms (which is an anomaly). Without the occurrence of high waves, the scour hole apparently developed first in vertical direction, before it widened in horizontal direction.

\section{Dredged hole}

The borrow area north of the dam (Figure 3), which was intended to develop into a tidal ebb-channel, indeed changed in that direction. The maximum dredged depths down to MSL $-15 \mathrm{~m}$ reduced rapidly to not deeper than MSL $-10 \mathrm{~m}$ two years later. While the MSL - $7 \mathrm{~m}$ depth contour of the dredged borrow area and that of the inlet channel Robbengat were not connected in June 1995, they were in March 1997 (see Figure 5). Once the borrow area stretched in east-west directions and became "connected" with the inlet channel Robbengat and with the scour hole, it migrated in northward direction under the influence of the eastward resultant sediment transport and the west-to-east tidal wave propagation.

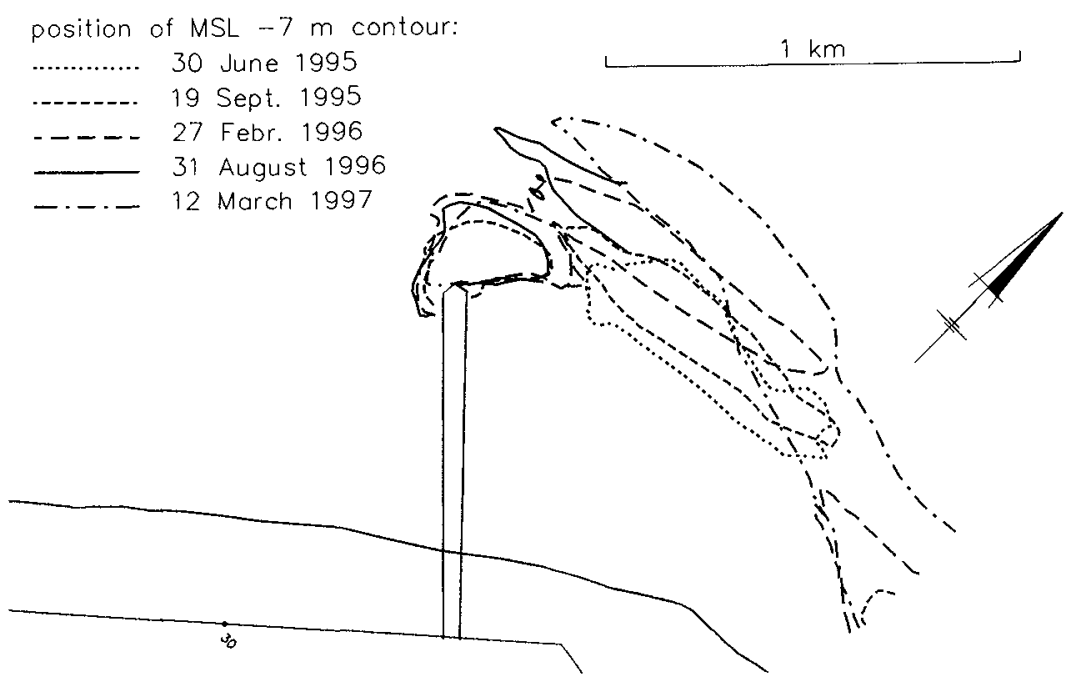

Figure 5 Movements of the MSL $-7 \mathrm{~m}$ depth contour 


\section{Coastal area north of the dam}

Immediately after the dam construction, significant accretion rates were found in the area to the north of the dam. This area continued to accumulate sand (Figure 4), albeit at a steadily slower rate. In the period July - September 1995 a resultant sand accumulation of more than $70,000 \mathrm{~m}^{3}$ per month was found in an area of some $0.4 \mathrm{~km}^{2}$. About one year later this accretion rate had reduced to some $30,000 \mathrm{~m}^{3}$ per month. Between the coastline of Texel, the dam and this accretion area, a small shortcut gully was present till early 1998, when it silted up.

\section{Coastal area south of the dam}

If we consider an area from the dunefoot to a shore-parallel line through the tip of the dam, and from the dam to a position $2.5 \mathrm{~km}$ south of the dam (Figure 4), then the total sand accumulation in this area in the period $1995-1997$ is $475,000 \mathrm{~m}^{3}$ per year. This accretion can be attributed to the effect of the long dam; nourishments have not been carried out in that period.

If we disregard the upper part of the profiles, above MSL $-1.5 \mathrm{~m}$, then the observations show that initially erosion took place $\left(70,000 \mathrm{~m}^{3}\right.$ in the period July - September 1995). In volumetric sense not much changed in the foreshore area in the winter of 1995 / 1996. But after the winter of $1996 / 1997$, when westerly storms had occurred, accretion of more than $300,000 \mathrm{~m}^{3}$ was observed. This demonstrates the importance of higher waves for the shoreward transport of sand from greater depths.

\section{Model predictions}

A numerical model of the entire tidal inlet system including the long dam and dredging works (Figure 3) was set up. The model is based on the DELFT3D software package, which is described in more detail elsewhere in these proceedings (Roelvink, Boutmy and Stam, 1998). The model computes the tidal wave propagation, the tide-, wave- and wind generated flow conditions, the short wave conditions, sediment transport and seabed changes. The model is of the medium term morphodynamic type (MTM-model: De Vriend, e.a., 1993). A limited number of input conditions (waves, tides, wind) have been selected in such a way that they represent the annual sediment transports.

Figure 6 shows, as an example, the computed tide-averaged sediment transports in the vicinity of the dam for one of the selected wave conditions "West-High" (at deep water: $\mathrm{H}_{\mathrm{s}}=3.1 \mathrm{~m}, \mathrm{~T}_{\mathrm{p}}=7.6 \mathrm{~s}$, from $268^{\circ} \mathrm{N}$ ). These transports follow after one year of morphodynamic simulation, so when the deepest portion of the dredged borrow area have already largely silted up.

An interesting detail in the resultant sediment transport patterns was observed near the dredged borrow area. Here, the resultant sediment transport at the start of the morphodynamic simulation is directed from two sides towards the center of the borrow area, leading to a steady siltation of the center of the dredged hole. The flood-dominance on the west-side of the borrow area is due to relaxation effects: during flood the incoming concentration vertical is over-saturated while during eb the incoming concentration vertical is under-saturated. 


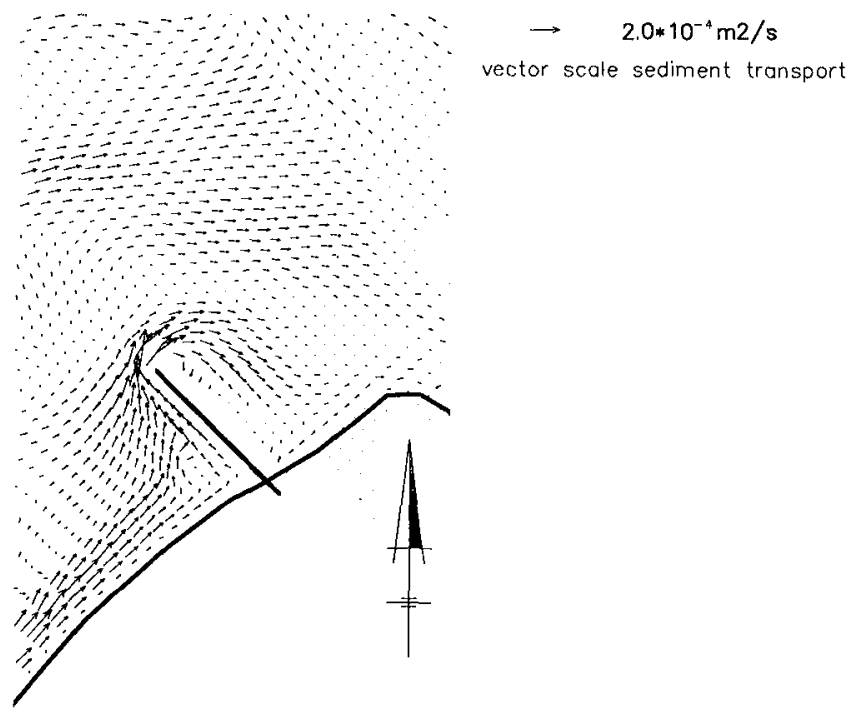

Figure 6 Tide-averaged sediment transport

A direct confrontation between the model predictions and the observations is given in Table 2 below. It gives the volumetric changes over a period of two years (1995 . 1997) for the five areas as indicated in Figure 3. It is noted that this table is not the only source for comparison: for that it lacks too much information on details of smaller scale phenomena

\begin{tabular}{|l|c|c|c|r|r|r|r|}
\hline \multicolumn{1}{|c|}{$\begin{array}{c}\text { Area } \\
\text { (Figure 3) }\end{array}$} & $\begin{array}{c}\text { Surface } \\
\left(\mathrm{m}^{2}\right\}\end{array}$ & \multicolumn{3}{|c|}{ Reference computation } & \multicolumn{2}{c|}{ Observations (Rakhorst, 1997) } \\
\cline { 3 - 8 } & $\begin{array}{c}\text { Sedimentation } \\
\left(\mathrm{m}^{3}\right)\end{array}$ & $\begin{array}{c}\text { Erosion } \\
\left(\mathrm{m}^{3}\right)\end{array}$ & $\begin{array}{c}\text { Volumetric } \\
\text { changes }\left(\mathrm{m}^{3}\right)\end{array}$ & $\begin{array}{c}\text { Sedimentation } \\
\left(\mathrm{m}^{3}\right)\end{array}$ & $\begin{array}{c}\text { Erosion } \\
\left(\mathrm{m}^{3}\right)\end{array}$ & $\begin{array}{c}\text { Volumetric } \\
\text { changes }\left(\mathrm{m}^{3}\right)\end{array}$ \\
\hline South & 510,000 & 169,000 & $-25,000$ & 144,000 & 354,000 & 0 & 354,000 \\
Scour hole & 172,000 & 16,000 & $-115,000$ & $-99,000$ & 0 & $-466,000$ & $-466,000$ \\
North & 485,000 & 32,000 & $-323,000$ & $-291,000$ & 972,000 & 0 & 972,000 \\
South west & $1,278,000$ & 260,000 & $-600,000$ & $-340,000$ & 987,000 & $-48,000$ & 939,000 \\
Northeast & 785,000 & 156,000 & $-2,237,000$ & $-2,081,000$ & 15,000 & $-1,040,000$ & $-1,025,000$ \\
\hline
\end{tabular}

Table 2: Computed and observed volumetric changes (1995 - 1997)

From the confrontation of the predictions with the observations it follows that:

- The predicted volume of the scour hole is much smaller than observed. Especially the maximun depth of the scour hole was not predicted (MSL - $7 \mathrm{~m}$ in stead of MSL $-18 \mathrm{~m}$ ).

- The dredged borrow area north of the dam also stretched and aligned with the inlet's channel Robbengat in the computations. It even showed a tendency for a northward migration although not at the same rate as in the observations. A weak point is that the computed total volumetric changes in the large area NorthWest does not correspond with the observations. 
- The accumulation of sand north of the dam was not predicted by the model. This could be related to the smaller scour hole (less sand available) or could be due to a too much restricted horizontal eddy exchange just behind the dam.

- The computed accretion south of the dam is almost half the observed accretion. Apparently, too much of the longshore sediment transport is directed in seaward direction along the dam, in stead of being stopped. This may also be one of the reasons why the computed scour near the tip of the dam remains so limited.

The conclusion that follows is that predictions with a state-of-the-art numerical morpho-dynamical model using "standard model settings", may still differ considerably from actual developments. This is even more true when looking at smaller-scale morphological developments.

\section{$\underline{\text { Sensitivity computations }}$}

The following series of sensitivity computations with the numerical model were carried out to get a better understanding of the behaviour of the model and to improve our knowledge on how these type of models should be designed and operated for the current type of applications:

- Computation with a one-week stornl-condition;

- Computation not with a full harmonic analysis of the tide, but by only applying the A0, M2 and M4 tidal constituents. The phases of these constituents were then varied to study the sensitivity of the tide-averaged sediment transport on the modelled phase difference between the M2 and M4 constituents:

- Computation with another tidal schematization;

- Computation with a different model boundary at the tidal flood basin;

- Computations with different values for the dispersion coefficient in the flow and sediment transport modules;

- Computation including a schematised reproduction of spiral flow;

- Computation with an adjusted bed roughness. The spatial differences in the bed roughness have been determined in such a way that it reflects the influence of larger-scale horizontal eddies on the bed shear stress. The applied method can only be regarded as a first attempt to schematise the complex influence of large-scale turbulence on the sediment transport capacities behind structures like the long dam;

- Computation with a different chronology in the wave and tidal conditions.

It goes beyond the scope of this paper to present the findings from the above set of model computations. Details can be found in Roelvink, van Holland and Steijn (1998). Yet, the following recommendations followed for improving the model:

- Take into account the actual chronology in the wave conditions for the simulated period. As stated before, the season 1995 / 1996 was completely different in terms of westerly heavy winds, than the $1996 / 1997$ season. In the improved model hindcast (see below), it was therefore decided to run the model for its first year with no waves, and for its second year with a schematisation of the actually occurring wave 
conditions. This appeared to be especially important for the rapid development of the scour hole.

- Take into account the effect of spiral flow. This phenomenon appeared to be important for the curving of the new channel through the dredged borrow area. Spiral flow also appeared to be important for additional sand movement towards the inner bend of the curved channel, that is towards the accretion zone north of the dam.

- Use spatially varying bed roughnesses, in such a way that they represent the effect of increased turbulence behind the long dam.

\section{Results from the improved model hindcast}

With the improved model a new hindcast was made of the morphological developments in the period 1995 - 1997. Table 3 summarises for the same areas as in Table 2, the computed and observed volumetric changes after one year (1996) and after two years (1997).

\begin{tabular}{|l|c|c|c|c|c|c|}
\hline \multicolumn{1}{c|}{$\begin{array}{c}\text { Area } \\
\text { (Figure 3) }\end{array}$} & \multicolumn{3}{|c|}{ Improved hindcast } & \multicolumn{3}{c|}{ Observations (Rakhorst, 1997) } \\
\cline { 2 - 7 } & $\begin{array}{c}\text { Sedimentation } \\
\left(\mathrm{m}^{3}\right)\end{array}$ & $\begin{array}{c}\text { Erosion } \\
\left(\mathrm{m}^{3}\right)\end{array}$ & $\begin{array}{c}\text { Volumetric changes } \\
\left(\mathrm{m}^{3}\right)\end{array}$ & $\begin{array}{c}\text { Sedimentation } \\
\left(\mathrm{m}^{3}\right)\end{array}$ & $\begin{array}{c}\text { Erosion } \\
\left(\mathrm{m}^{3}\right)\end{array}$ & $\begin{array}{c}\text { Volumetric changes } \\
\left(\mathrm{m}^{3}\right)\end{array}$ \\
\hline South & 11,000 & $-31,000$ & $-20,000$ & 12,000 & $-31,000$ & $-19,000$ \\
Scour hole & 22,000 & $-310,000$ & $-288,000$ & 0 & $-497,000$ & $-497,000$ \\
North & 147,000 & $-63,000$ & 84,000 & 572,000 & $-96,000$ & 476,000 \\
Southwest & 945,000 & $-46,000$ & 899,000 & 641,000 & $-109,000$ & 532,000 \\
Northeast & 232,000 & $-906,000$ & $-675,000$ & 127,000 & $-495,000$ & $-368,000$ \\
\hline
\end{tabular}

a) After 1 year (1995-1996); no waves

\begin{tabular}{|c|c|c|c|c|c|c|}
\hline \multirow{2}{*}{$\begin{array}{c}\text { Area } \\
\text { (Figure 3) }\end{array}$} & \multicolumn{3}{|c|}{ Improved hindcast } & \multicolumn{3}{|c|}{ Observations (Rakhorst, 1997) } \\
\hline & $\begin{array}{c}\text { Sedimentation } \\
\left(\mathrm{m}^{3}\right)\end{array}$ & $\begin{array}{c}\text { Erosion } \\
\left(\mathrm{m}^{3}\right)\end{array}$ & $\begin{array}{c}\text { Volumetric changes } \\
\left(\mathrm{m}^{3}\right)\end{array}$ & $\begin{array}{c}\text { Sedimentation } \\
\left(\mathrm{m}^{3}\right)\end{array}$ & $\begin{array}{c}\text { Erosion } \\
\left(\mathrm{m}^{3}\right)\end{array}$ & $\begin{array}{l}\text { Volumetric changes } \\
\qquad\left(\mathrm{m}^{3}\right)\end{array}$ \\
\hline So & & $-281,000$ & -53000 & 354,000 & 0 & 354,000 \\
\hline $\mathrm{Sc}$ & & & & 0 & $-446,000$ & -44 \\
\hline North & 00 & -12 & 00 & 972,000 & 0 & 972,000 \\
\hline Southwest & 538,000 & $-882,000$ & $-344,000$ & 987,000 & $-48,000$ & 939,000 \\
\hline Northeast & 299,000 & $-2,515,000$ & $-2,216,000$ & 15,000 & $-1,040,000$ & $-1,025,000$ \\
\hline
\end{tabular}

b) After 2 years (1995-1996)

Table 3: Comparison between predicted and observed volumetric changes

Figures 7 and 8 further show the computed sedimentation and erosion patterns in the vicinity of the long dam, respectively after one and two years of morphodynamic simulation. Figure 8 can be compared with Figure 4, which was based on the observations. 

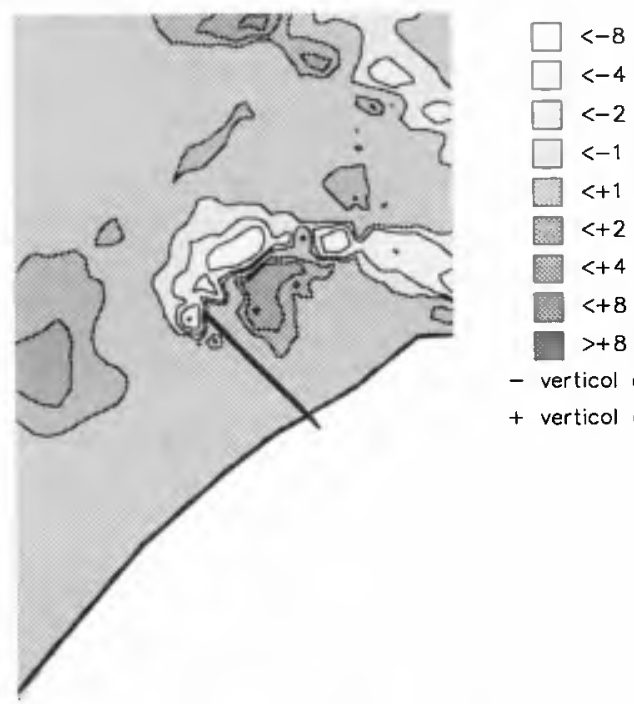

- verticol erosion in $\mathrm{m}$

+ verticol occretion in $m$

Figure 7 Computed sedimentation and erosion 1995 - 1996 (no waves)

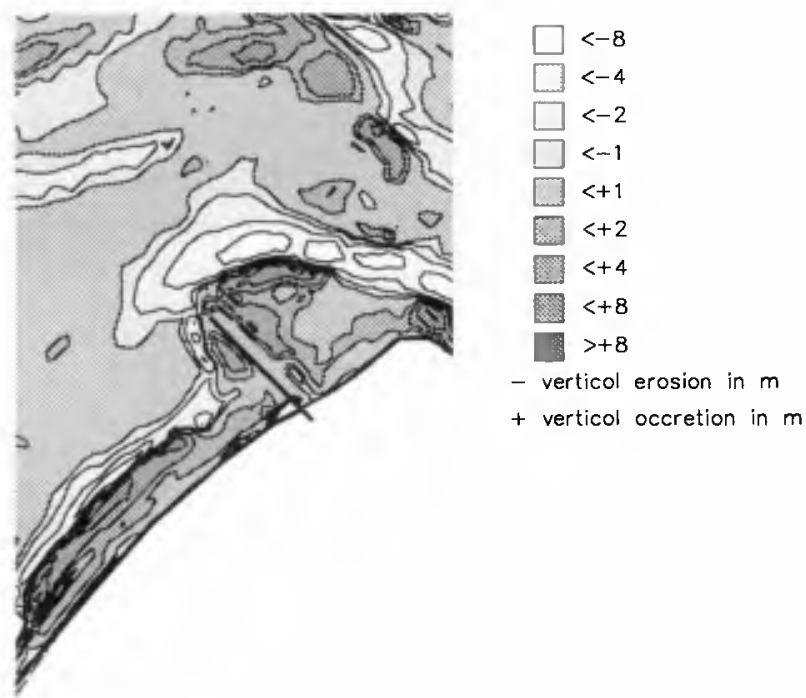

Figure 8 Computed sedimentation and erosion 1995 - 1997 


\section{Conclusions}

From a comparison of the results of the improved hindcast with the observations it follows that:

- The maximum depth in the scour hole now is computed at MSL - $14 \mathrm{~m}$ after six months of simulated time, which is not far from the observed maximum depth of $18 \mathrm{~m}$;

- In the first simulated year there is hardly any accretion south of the dam, which corresponds with the observations. In the next year, when waves are considered in the computations, there is significant accretion, which also fits with the observations.

- The coastal zone north of the dam now also accretes (contrary to the reference computation), which agrees with the observations. In absolute sense, however, there are still discrepancies between the computed accretion rates and the observed ones.

- The model shows that the dredged borrow area quickly develops into a tidal channel (in line with the Robbengat in the inlet throat), which starts to migrate in northward direction. This corresponds with the oservations, albeit that the curvature of the channel as well as the migration speed differ.

- The coastal profiles in front of the north-coast of Texel (south of the dam) develop into unrealistic profiles, which would be corrected if cross-shore transport effects by waves were taken into account.

In summary, it can be concluded that the improved model simulates most of the observed morphological changes. The largest uncertainties are the modelling of the turbulence effects around the dam and the modelling of the effect of waves and turbulence on the sediment transport. For a correct representation of the morphological developments, the behaviour of the applied sediment transport formula as a function of the combined flow, turbulence and orbital velocities, is of special importance.

\section{Final remarks}

The long dam has been effective in the protection of the north coast of Texel. Contrary to the predictions it has not worsened the situation directly north of the dam. Possible negative consequences for the sand balance of the downdrift island Vlieland have not yet been recorded, but that is probably a matter of time. The morphological response have largely been restricted to the immediate surroundings of the works. But again, this may be a matter of time. After all, the new elongated tidal channel Robbengat has proven to play an important role in the filling and emptying of the flood basin.

Rijkswaterstaat will continue to monitor the situation in the tidal inlet and around the dam. We expect that after some time this data set will form a very valuable source for experimental testing of existing and new model concepts. 


\section{Acknowledgements}

The work is carried out as part of the Coast*2000 programme of the Dutch Ministry of Transport and Public Works (Rijkswaterstaat). The authors further want to acknowledge the staff of the Regional Directorate North-Netherlands of Rijkswaterstaat for visualising the data sets of the Eijerlandse Gat.

\section{$\underline{\text { References }}$}

De Vriend, H.J., J. Zyserman, J. Nicholson, J.A. Roelvink, P. Pechon and H.N. Southgate, 1993. Medium-term 2DH coastal area modelling. Coastal Engineering, 21 (1993) pp. 193-224

Hartsuiker, G., 1991. Coastal Defence Eijerland- hydraulic morphologic effect-study; phase 1. Delft Hydraulics report number H124l, Delft, June 199l (in Dutch)

Negen, E.H., 1993 Morphologic investigations using 2DH numerical models at Eijerland (Texel). M.Sc. Thesis Delft University of Technology. Also: Delft Hydraulics report number H1887, Delft, The Netherlands (in Dutch).

Rakhorst, D. 1997. Morphological evaluation Dam at Eijerland (third report). Rijkswaterstaat, Regional Directorate North Holland, december 1997 (in Dutch).

Rakhorst, D., D. De Wilde and C. Schot, 1997. Seaward Coastal Defence Scheme Eijerland. Terra et Aqua - number 67 - june 1997, pp. 3-13.

Ribberink, J.S. and J.H. De Vroeg, 1992. Coastal Defence Eijerland - hydraulic morphologic effect-study phase II. Delft Hydraulics report number H1241, May 1992

Ribberink, J.S., E.H. Negen and G. Hartsuiker, 1995. Mathematical Modeling of coastal morphodynamics near a tidal inlet system. Coastal Dynamics '95, ASCE, Gdanks, Poland.

Roelvink, J.A., A.E.G. Boutmy and J.M.T Stam, 1998. A simple method to predict long-term morphological changes using complex model results. These Proceedings.

Roelvink, J.A., G. van Holland and R.C. Steijn, 1998. Sensitivity computations Eijerland and SW-Texel - phase 1 Eijerland. Report jointly prepared by Alkyon (number A266) and Delft Hydraulics (number Z2430), May 1998, (in Dutch)

Rijkswaterstaat, 1990 A new coastal defence policy for the Netherlands. Ministry of Public Works, the Netherlands 